\title{
Microstructural Study of the Interfacial Transition Zone in Concrete using Optical Microscopy
}

\author{
Khairul Nizar Ismail ${ }^{1, *}$, and Tan Let Hui ${ }^{1}$ \\ ${ }^{1}$ School of Environmental Engineering, Kompleks Pusat Pengajian Jejawi 3, \\ Universiti Malaysia Perlis, 02600 Jejawi, Perlis, Malaysia.
}

\begin{abstract}
This paper presents an overview on the optical microstructural features in concrete. Microstructure is the small scale structure of a material, defined as the structure of a prepared surface of material as revealed by a microscope. The concrete specimens with the manipulation of water/cement ratio 0.3-0.7 (increment of 0.1 ) in the concrete mix design were used to study the optical microstructural features in concrete and to validate the existence of an interfacial transition zone (ITZ) in concrete. USB Digital Microscope is used to analyse the formation mechanism of microstructure in concrete where the optical microstructural images is analyse via respective curing periods of $1,7,28$ and 56 days. The microstructure features are discussed with respect to their influence on the strength development of concrete.
\end{abstract}

\section{Introduction}

Concrete is the single most widely used material in the world, however, concrete behaviour is complex at it microscopic level. Microstructure can be observed by using a range of microscopy methods. The typical practiced are the optical microscopy and SEM analysis. It is crucial to select the microscopy methods by considering the length scale of the observations to study the microstructure of a material. Optical microscopy is applied to supplement the cement matrix composite test results. The advantage of using an optical microscope in concrete examination is that, it offers larger field of view [1].

Microscopic complex mass in concrete is view as a three-phase composite structure: aggregate, interfacial transition zone (ITZ), and matrix [2]. Interfacial transition zone (ITZ) is defines as a thin layer region of the cement paste around the aggregate particles and ITZ exists around both the coarse and fine aggregates [3]. The formation mechanisms consisted different microstructure of surrounding hydrated cement paste which is generated during casting of fresh concrete with a water/cement (w/c) ratio gradient develops around the aggregate particles. The properties of the microstructures: aggregate, cement bulk paste and particularly the $\mathrm{w} / \mathrm{c}$ ratio of the mixture are significant factors that determining the concrete composite properties [4]. Zhang [5] carried out a research in determination of the

\footnotetext{
* Corresponding author: nizar@unimap.edu.my
} 
microstructural features in concrete due to the effect of curing conditions on the manipulation of $w / c$ ratio. It is however, w/c ratio and cement content have the limited effect on the microstructure in concrete; therefore, it is necessary to identify the modification of the microstructure towards the strength of concrete.

This research aims to describe the optical microstructure features in different concrete models in order to understand the strength development and performance properties of concrete. By understanding the microstructures of concrete is comprised of an interfacial zone of which the properties is differ from the bulk matrix and aggregates but the ITZ is not necessarily an intrinsic feature of concrete instead it depends on the degree of hydration; therefore, the water/cement ratio in the mix design is importance.

\section{Materials and experimental methods}

\subsection{Materials}

This research used:

i. $\quad$ Ordinary Portland cement (OPC - 42.5) (ASTM Type 1);

ii. Tap water is used for both the concrete mixes and curing. The temperature ranged between $20^{\circ} \mathrm{C}-27^{\circ} \mathrm{C}$. The water used should not contaminate.

iii. Coarse aggregate used was crushed granite stone with maximum size of $20 \mathrm{~mm}$ and it properties is determined from the specific gravity test.

iv. Natural river sand with sand fraction passing through $600 \mu \mathrm{m}$ sieve was used and it properties are determined through the specific gravity test.

\subsection{Mixture proportions}

The concrete mixture proportion is design based on the British Standard on design of normal concrete mixes. Concrete with water/cement ratios of 0.30 to 0.70 with an increment of 0.10 was prepared. The design characteristic strength of the concrete for this research is $25 \mathrm{MPa}$. The slump for $\mathrm{w} / \mathrm{c}$ ratio $=0.30-0.40$ is $10-30 \mathrm{~mm}$ and the slump for w/c ratio $=0.50-0.70$ is $30-60 \mathrm{~mm}$.

\subsection{Curing condition}

Selected curing ages of 1,7,28 and 56 days were used to analyze the microstructural features influences on the strength of concrete. One day curing age of this test was defined as the time spent for curing in water tank after removing the concrete specimens from the mold; before that, the concrete was in the process of molding and put in air for $24 \mathrm{~h}$. The concrete casting process is carried out in accordance with BS EN 12390-2:2009, making and curing specimens for strength tests.

\subsection{Concrete compressive test}

The concrete compressive strength test was determined according to BS EN 12390-3:2009 at $1,7,28$, and 56 curing ages. Total of 12 cubes samples were tested. The results obtained are the average compressive strength of the 3 cubes samples test results for each curing ages. The cubes are tested on the face perpendicular to the casting face. 


\subsection{Optical microstructure test}

At the later stage, the microstructural test is carried out on each specimens when it achieved the desired curing age such that at 1, 7, 28 and 56 days. The specimens that used to undergo the optical microstructure test must be a thin flat surface so that to obtain a clearer images and is prepared from the specimens casted in cylinder molds and cutting with the concrete cutting machine. A USB Digital Microscope is used where the microscope camera attaches directly to the USB port of a computer, eyepieces are not required and the images are shown directly on the monitor.

\section{Results and discussions}

\subsection{Effect of water/cement (w/c) ratio on compressive strength of normal concrete}

The w/c ratio, largely determines the strength and durability of the concrete when it is cured properly. When the w/c ratio is high which mean the bigger amount of water in a concrete mix, the more dilute the cement paste will be and affects the compressive strength and leads to the porosity. The more the w/c ratio is increased; the strength of the resulting concrete is reduced. The results for 1, 7, 28 and 56 days curing ages with regard to test compressive strength for all the concrete cubes samples being computed in table and shown in Fig 1.

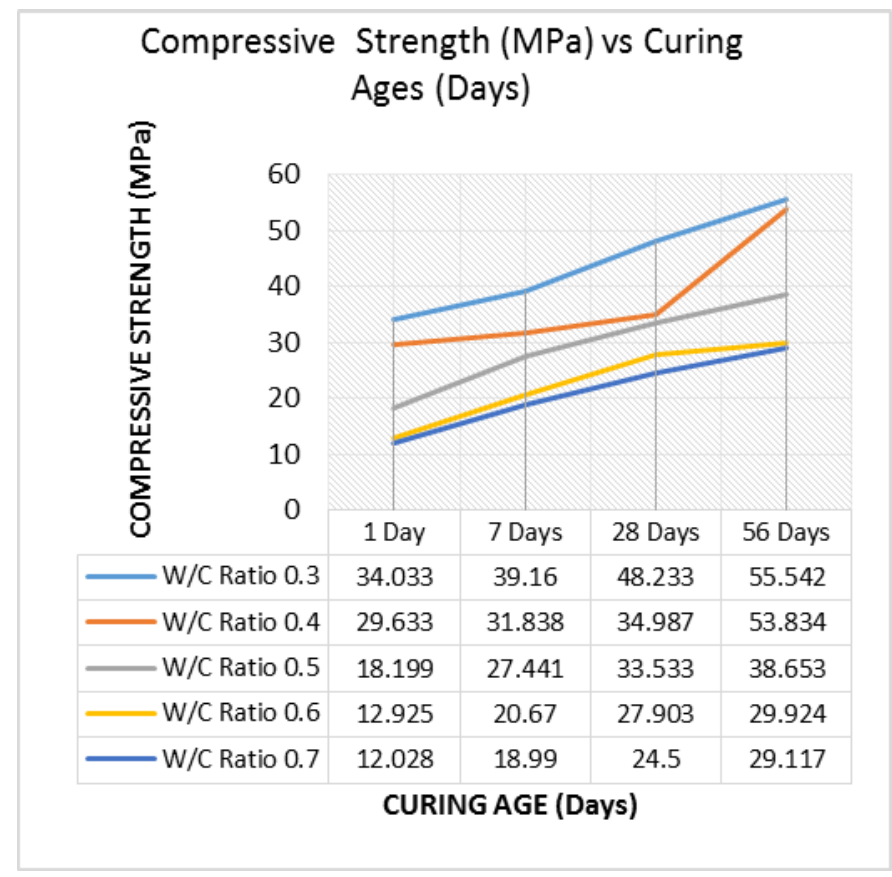

Fig. 1. Graph of Compressive Strength (MPa) against Curing Ages (Days) 


\subsection{Optical microstructural analysis and development of interfacial transition zone in concrete for different curing ages}

It can be observed that, the optical microstructure in normal concrete consisted of three distinct phases and boundaries. The three phases in concrete consisted of the aggregates phase, bulk cement paste and also the interfacial transition zone (ITZ). In addition, pores due to inefficient packing of concrete may also be observed using the optical microscope. The microstructural analysis images of concrete samples with water/cement ratio of 0.5 are shown in Fig. 2. The ITZ is presence due to the potentially effect from the inefficient packing between the aggregate surface and cement particles. However, the thickness of the ITZ layer will decrease or even disappeared in respond to it increasing in curing ages.
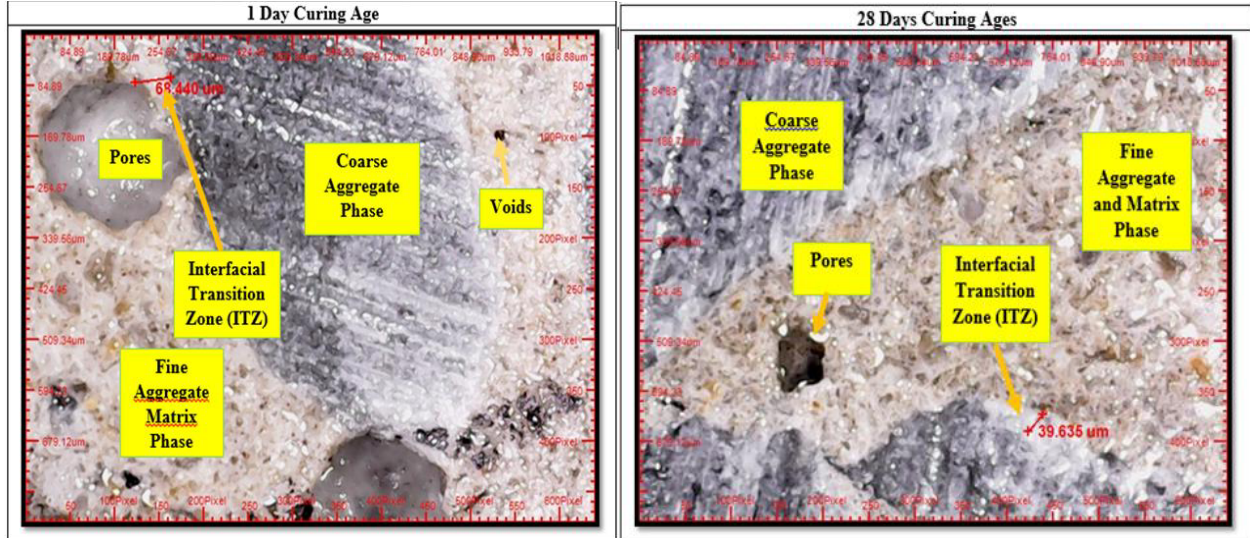

Fig. 2. Microstructural analysis images on concrete samples with water/cement ratio of 0.5 .

Fig 3 shows the thickness $(\mu \mathrm{m})$ of the interfacial transition zone (ITZ) against the curing ages (Days) for the five concrete samples with w/c ratio from 0.3-0.7. It was found that, as the $\mathrm{w} / \mathrm{c}$ ratio is low, the thickness of the ITZ layer is significantly reduced and hence enhances the microstructure of the interface region. In addition, lower w/c ratio created thinner ITZ and help to increase the concrete strength since the microstructures are denser packed to each other. This is also justified w/c ratio of 0.3 has the highest compressive strength but the thinnest ITZ layer during the 28 days. 


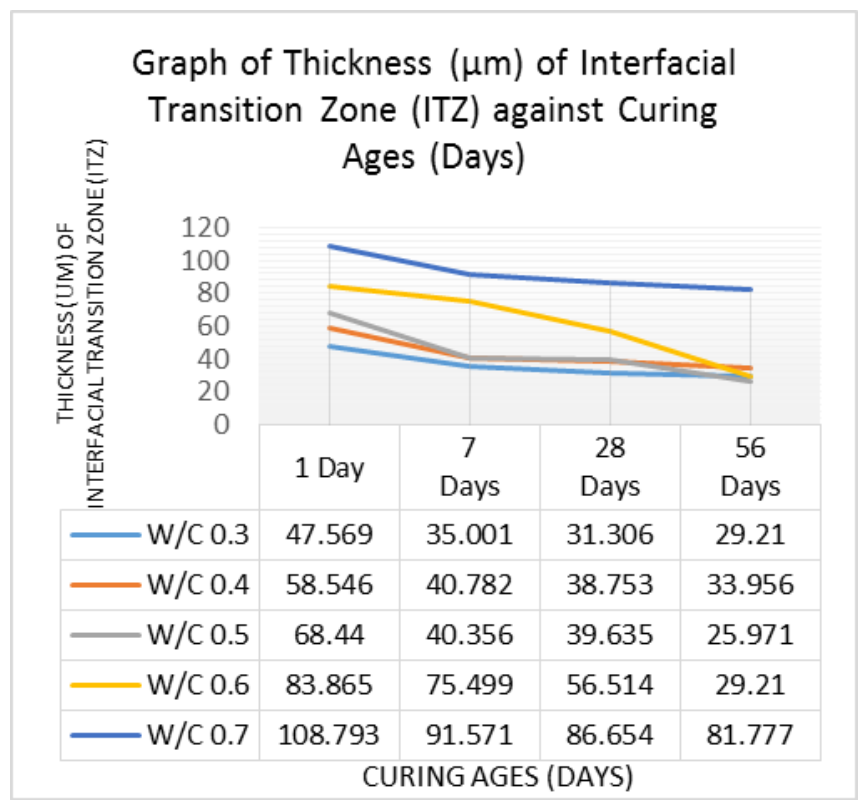

Fig 3: Graph of thickness $(\mu \mathrm{m})$ of the interfacial transition zone (ITZ) against the curing ages (Days) for the five concrete samples with $w / \mathrm{c}$ ratio from $0.3-0.7$.

\section{Summary}

The ITZ is existed in the concretes for w/c ratio range from $0.3-0.7$ and it is detectable by using the optical microscope. However, there is no constant trend can be observed for the existence of ITZ. It can be summarized that the ITZ thickness depends on $\mathrm{w} / \mathrm{c}$ ratio. The higher w/c ratio resulted in thicker ITZ layer due to higher water concentration of the concretes and slower hydration process. From the optical microstructural analysis, it can be concluded that the formation mechanisms of the microstructure in concrete can be described as the continuous development of the microstructure with respective to its curing ages.

\section{References}

1. A.M. Brandt, N.D. Jozwiak, Z. Ranachowski, Advances in Civil Engineering Materials $1, \mathbf{1}, 1,(2012)$

2. L.S. Karen, R. Li, J. Pei, B. Xue, Constr. Build. Mater., 101, 410, (2004)

3. B.D. Mason, H.B. Sarnes, D. Siamond, D.L. Wolch, Cem. Concr. Res., 32, 1291, (2000)

4. J. Halbiniak, G. Prolopski, Cem. Concr. Res., 30, 579 (2000)

5. Y.H. Zhang, Journal of Concrete and Structure, 3, 146 (2010) 